A C T A C H E M I C A S C A N D I N A V I C A

\title{
Extraction of Mucopolysaccharides from Connective Tissue
}

\author{
ANUND HALLEN
}

Chemistry Department II, Karolinska Institutet, Stockholm, Sweden

\begin{abstract}
Human nucleus pulposus and umbilical cords were extracted with water, and the extracts and residues obtained on centrifugation were analyzed for mucopolysaccharides. It was found that, in the extract of nucleus pulposus, the yield of keratosulphate was smaller than that of chondroitin sulphate. In the umbilical cord extract, the yield of chondroitin sulphate was smaller than that of hyaluronate.
\end{abstract}

Tt is a general experience that the chondroitin sulphate of cartilage is so $I_{\text {firmly bound that a good yield can be obtained only with the use of drastic }}$ methods for preparation, such as extraction with strong alkali ${ }^{1-4}$, or disintegration of the tissue by proteolytic digestion ${ }^{5-7}$, by autodigestion ${ }^{8}$ or by vigorous mechanical treatment ${ }^{9}$. With neutral salt solutions, only small amounts of mucopolysaccharides are extracted ${ }^{10,4}$. Even such a strong solution as $10 \%$ calcium chloride ${ }^{11}$ is ineffective ${ }^{10}$, whereas $1 \%$ potassium carbonate in $30 \%$ potassium chloride ${ }^{8}$ is moderately effective in extracting the chondroitin sulphate of cartilage.

Differences are, however, present between various tissues with respect to the ease with which their mucopolysaccharides can be extracted. For instance, a large part of the hyaluronate can be extracted from umbilical cords with such a mild agent as distilled water ${ }^{\mathbf{1 2}}$.

It was considered of interest to investigate in some detail differences in the extractability of individual mucopolysaccharides. An account is given in the following of experiments with adult human nucleus pulposus, and with human umbilical cords, freed from vessels. It seems to be well established ${ }^{13-17}$ that chondroitin sulphate and keratosulphate are the main polysaccharides in the nucleus pulposus. As indicated by the results of infrared spectrum ${ }^{18}$ and alcohol fractionation studies ${ }^{17}$, the chondroitin sulphate is the 6 -isomer. The mucopolysaccharides of the umbilical cord are less well characterized, although hyaluronate is known to be the main polysaccharide ${ }^{12,19,16}$. According to results of Meyer et al. ${ }^{12,19,20}$ and of Mathews ${ }^{21}$, chondroitin-6-sulphate is also present. 


\section{EXPERIMENTAL}

Prparation of the tissues. Healthy intervertebral discs were taken at autopsy from a 59-year-old man, one day after death. The nucleus pulposus, the central part of the disc, was dissected free from the surrounding annulus fibrosus.

Human umbilical cords were obtained not more than one day after delivery, and were freed from blood vessels. It was found that the most suitable procedure was to cut the cord into $2 \mathrm{~cm}$ pieces, thread a peg through the vein, fix the peg on a stand and dissect out the stroma with a razor-blade. The arteries were then removed by blunt dissection.

The tissues were homogenized by grating and grinding. The doughy material was stored for some weeks at $-15^{\circ} \mathrm{C}$, and thawed immediately before use.

Extraction of the mucopolysaccharides. About $4 \mathrm{~g}$ each of wet nucleus pulposus and umbilical cord tissues were extracted with $250 \mathrm{ml}$ of distilled water overnight at $0^{\circ} \mathrm{C}$, under gentle stirring. Centrifugation for $20 \mathrm{~min}$ at about $15,000 \mathrm{~g}$ yielded a clear extract and a residue from both tissues. After evaporation of the extract in vacuo to a small volume, the material was freeze-dried.

Analysis of the freeze-dried extracts and residues. Hexosamines and disaccharides were analyzed with the chromatographic method described earlier ${ }^{16}$, glucosamine and galactosamine after hydrolysis for $8 \mathrm{~h}$ in $6 \mathrm{M}$ hydrochloric acid, chondrosin and hyalobiuronic acid after hydrolysis for $2.5 \mathrm{~h}$ in $0.6 \mathrm{M}$ hydrochloric acid. Sulphate sulphur was determined gravimetrically as barium sulphate, after hydrolysis for $4 \mathrm{~h}$ with $4 \mathrm{M}$ hydrochloric acid. Nitrogen was determined by a micro-Kjeldahl procedure. Collagen was determined by means of hydroxyproline analysis ${ }^{22,23}$. The collagen content was obtained by multiplying the hydroxyproline value by the factor 7.5.

The ratio of galactose/glucuronic acid in the nucleus pulposus extract and residue was determined colorimetrically after partial purification of the mucopolysaccharides. Samples of the extract and residue were boiled with water for $30 \mathrm{~min}$, and submitted to digestion with glycerol extracts of pig pancreas and intestinal mucosa 6,13 for 2 months. To ensure complete hydrolysis of the proteins, a second digestion with papain ${ }^{7}$ was carried out overnight, after preliminary heat denaturation in a boiling water bath for $15 \mathrm{~min}$. The mucopolysaccharides, together with some impurities, were precipitated by the addition of one volume of $10 \%$ calcium chloride in glacial acetic acid and four volumes of $10 \%$ calcium chloride in ethanol. The mucopolysaccharides were then extracted from the precipitate by stirring vigorously with distilled water. The galactose content of the clear and colourless solutions obtained on centrifugation was determined with the anthrone method of Scott and Melvin ${ }^{24}$, and the glucuronic acid content with the carbazole method of Dische ${ }^{25}$. The interference, amounting to some $10 \%$, of glucuronic acid in the anthrone reaction, and of galactose in the carbazole reaction was neglected. This approximation is possible provided that the galactose/glucuronic acid ratio does not differ greatly from 1 . The presence of interfering sugars other than galactose and glucuronic acid is not probable, but has not yet been experimentally excluded.

Table 1. Analyses of freeze-dried extracts and residues of nucleus pulposus and umbilical cord *.

\begin{tabular}{|c|c|c|c|c|c|c|c|c|}
\hline $\begin{array}{l}\text { Material } \\
\text { analyzed }\end{array}$ & $\begin{array}{c}\text { Moist- } \\
\text { ure } \\
\%\end{array}$ & $\underset{\%}{\text { Ash }}$ & $\begin{array}{c}\text { Colla- } \\
\text { gen } \\
\%\end{array}$ & $\begin{array}{c}\text { Nitro- } \\
\text { gen } \\
\%\end{array}$ & $\underset{\%}{\text { Sulphur }}$ & $\begin{array}{r}\text { Hex } \\
\%\end{array}$ & $\begin{array}{l}\text { amine } \\
\% \text { of } \\
\text { total }\end{array}$ & $\frac{\text { Hexosamine }}{\begin{array}{c}\text { Sulphur } \\
\text { molar ratio }\end{array}}$ \\
\hline $\begin{array}{l}\text { Nucleus } \\
\text { pulposus }\end{array}$ & & & & & & & & \\
\hline Extract: $0.42 \mathrm{~g}$ & 10.1 & 15.4 & 0.1 & 5.9 & 2.73 & 9.2 & 52 & 0.6 \\
\hline Residue: $1.32 \mathrm{~g}$ & 9.2 & 3.2 & 40.2 & 14.3 & 0.52 & 2.7 & 48 & 0.9 \\
\hline $\begin{array}{l}\text { Umbilical cord } \\
\text { Extract: } 0.36 \mathrm{~g}\end{array}$ & 5. & 22.1 & 0 & 8. & 0.2 & 2.0 & 66 & 1.8 \\
\hline Residue: $0.93 \mathrm{~g}$ & 11.3 & 2.7 & 50.3 & 14.8 & 0.10 & 0.4 & 34 & 0.7 \\
\hline
\end{tabular}

* Hexosamine content of freeze-dried tissues: nucleus pulposus $6.5 \%$; umbilical cord $1.3 \%$. 


\section{RESULTS AND DISCUSSION}

Behaviour of nucleus pulposus. As shown in Table 1, the hexosamines, i.e. glucosamine + galactosamine, were obtained in about $50 \%$ yield in the extract. The molar ratio of hexosamine/sulphate was close to 1 in the residue, but somewhat less in the extract, probably depending on the presence of sulphate ions. The collagen remained, as expected, quantitatively in the residue. The high nitrogen contents indicate the presence of protein other than collagen. Nitrogen values higher than expected from the collagen and hexosamine contents have proved to be a constant finding, even after careful exclusion of blood contamination and dialysis.

For a more detailed study of the hexosamines in the extract, another water extract was prepared from $13 \mathrm{~g}$ of a pooled nucleus pulposus sample. The molar ratio of hexosamine/sulphate was found to be 0.79 , but after dialysis it rose to 1.04. The ratio of glucosamine/galactosamine was 0.65 before dialysis, and 0.62 after, thus practically the same. The hexosamine losses during dialysis were negligible. These results are well compatible with the presence of keratosulphate and chondroitin sulphate.

Table 2. Molar ratios of sugar components in freeze-dried tissue specimens, extracts and residues of nucleus pulposus and umbilical cord *.

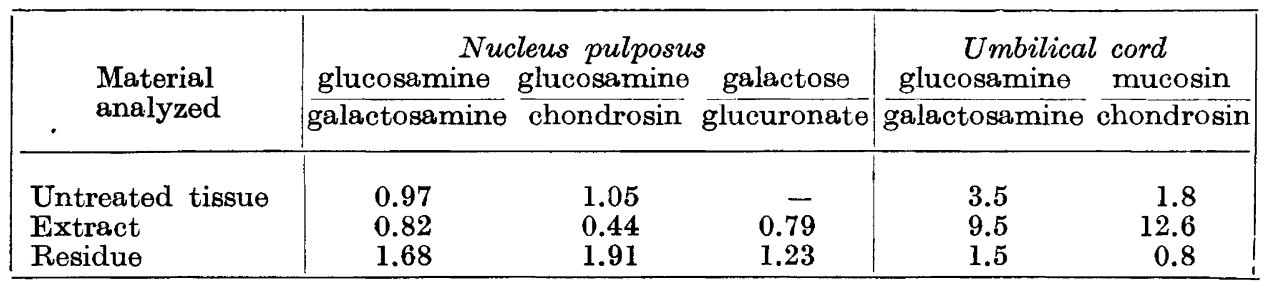

* Mucosin synonymous with hyalobiuronic acid. The glucosamine/galactosamine ratio in annulus fibrosus surrounding the nucleus pulposus was 0.89 .

As shown in Table 2, the ratio of glucosamine/galactosamine was lower in the extract than in the residue. This implies that the ratio of keratosulphate/ chondroitin sulphate was lower in the extract than in the residue. Further evidence is afforded by the fact that the ratio of glucosamine/chondrosin was lower in the mild acid hydrolysate of the extract than of the residue, as was the ratio of galactose/glucuronic acid.

In order to study the influence of salt on the extraction, 5-6 $\mathrm{g}$ of pooled nucleus pulposus were extracted with $500 \mathrm{ml}$ of $1 \%$ sodium chloride. The residue was then extracted twice with $250 \mathrm{ml}$ of $1 \%$ sodium chloride. The ratio of glucosamine/galactosamine, which was 0.89 in the original sample, was 0.57 in the first extract and 0.91 in the second. The third extraction yielded practically no material, the ratio in the residue being 2.00 . In another experiment, $10 \%$ calcium chloride was used; the ratio of glucosamine/galactosamine was 0.75 in the first extract, 1.03 in the second, 1.03 in the small amount of material obtained in the third extract, and 1.26 in the residue. In this experiment, as in that with $1 \%$ sodium chloride, all the material had been dialyzed before 
freeze-drying. The results indicate that salts do not influence the differences in extractability.

In the experiments with $1 \%$ sodium chloride and $10 \%$ calcium chloride, only some $1-2 \%$, and $2-3 \%$, respectively, of the collagen was obtained in the extracts. This is in accordance with findings of Davidson and Woodhall ${ }^{17}$. The yield of hexosamines in the extracts was the same as when distilled water was used, or slightly greater, in conformity with the results of Hass and Garthwaite ${ }^{10}$ in the case of cartilage.

Behaviour of umbilical cord. It is evident from Table 1 that the hexosamine/ sulphate ratio was fairly high in the extract, as could be expected in view of the predominance of hyaluronate, whereas the very approximate value of this ratio in the residue was lower. As seen in Table 2, the ratio of glucosamine/ galactosamine was much higher in the extract than in the residue. These results are in good agreement with those of Meyer and Palmer ${ }^{12}$, and indicate a higher hyaluronate/chondroitin sulphate ratio in the extract than in the residue. This is also borne out by the higher ratio of hyalobiuronic acid/chondrosin in mild acid hydrolysates of the extract than of the residue.

Interpretation of the results. The results of this study indicate that differences are present between the mucopolysaccharides with respect to their extractability. Thus, in nucleus pulposus keratosulphate is more difficult to extract than chondroitin sulphate, whereas in umbilical cord chondroitin sulphate is more difficult to extract than byaluronate. Since the experiments were performed with homogeneous tissues, the conditions of extraction of the individual mucopolysaccharides thus being comparable, these differences may reflect differences in the properties of the mucopolysaccharides themselves, of their complexes with non-collagenous protein ${ }^{26,27}$, or their attachment to the collagen fibers. Unfortunately, a detailed interpretation is, as yet, difficult, in view of our incomplete knowledge of the mucopolysaccharides and of the proteins in the connective tissue.

It is possible that the extractability of the mucopolysaccharide fraction may influence the physical and morphological properties of the tissue. For instance, the nucleus pulposus of a young subject is a viseous fluid, whereas in the old it is somewhat dry and firm and - in the highest age groups - is easily torn. This might be explained, to some degree, by an increase in the ratio of keratosulphate/chondroitin sulphate with age ${ }^{15,16}$, which - according to the results of the present investigation - would imply a shift to a less easily extractable mucopolysaccharide component. There are reasons to believe that the deposition of other materials that are difficult to extract, such as collagen and "lipofuscin", may also be of importance for the change in the nature of the tissue with age.

Acknowledgements. I am graatly indebted to Docent Lennart Rodén and Docent Sven Gardell for valuable discussions, as well as to Mrs. Ruth Flagell for skilful technical assistance. anslag.

The investigation has beэn aided by grants from Karolinska Institutets reservations-

\section{REFERENCES}

1. Krukenberg, C. F. W. Z. Biol. 20 (1884) 307.

2. Mörner, C. T. Skand. Arch. Physiol. 1 (1889) 210.

3. Levene, P. A. and LaForge, F. B. J. Biol. Chem. 15 (1913) 69.

4. Jorpes, E. Biochem. Z. 204 (1929) 354.

Acta Chem. Scand. 14 (1960) No. 8 
5. Schmiedeberg, O. Arch. exptl. Pathol. Pharmakol. Naunyn-Schmiedeberg's 28 (1891) 355.

6. Gardell, S. Arkiv. Kemi 4 (1952) 449.

7. Scott, J. E. in Glick, D. Methods of Biochemical Analysis 8 (1960) 145.

8. Einbinder, J. and Schubert, M. J. Biol. Chem. 185 (1950) 725.

9. Malawista, I. and Schubert, M. J. Biol. Chem. 230 (1958) 535.

10. Hass, G. M. and Garthwaite, A. B. A.M.A. Arch. Pathol. 33 (1942) 145.

11. Meyer, K. and Smyth, E. M. J. Biol. Chem. 119 (1937) 507.

12. Meyer, K. and Palmer, J. W. J. Biol. Chem. 114 (1936) 689.

13. Gardell, S. and Rastgeldi, S. Acta Chem. Scand. 8 (1954) 362.

14. Gardell, S. Acta Chem. Scand. 11 (1957) 668.

15. Hallén, A. Acta Chem. Scand. 12 (1958) 1869.

16. Hallén, A. Acta Chem. Scand. 13 (1959) 1919.

17. Davidson, E. A. and Woodhall, B. J. Biol. Chem. 234 (1959) 2951.

18. Orr, S. F. D. Biochim. et Biophys. Acta 14 (1954) 173.

19. Meyer, K., Davidson, E., Linker, A. and Hoffman, P. Biochim. et Biophys. Acta 21 (1956) 506.

20. Hoffman, P., Linker, A. and Meyer, K. Federation Proc. 17 (1958) 1078.

21. Mathews, M. B. Nature 181 (1958) 421.

22. Neuman, R. E. and Logan, M. A. J. Biol. Chem. 184 (1950) 299.

23. Martin, C. J. and Axelrod, A. E. Proc. Soc. Exptl. Biol. Med. 83 (1953) 461.

24. Scott, T. A. and Melvin, E. H. Anal. Chem. 25 (1953) 1656.

25. Dische, Z. J. Biol. Chem. 167 (1947) 189.

26. Schubert, M. Federation Proc. 17 (1958) 1099.

27. Muir, H. Biochem. J. 69 (1958) 195.

Received July 26, 1960. 